\title{
Effect of blue light on the photosynthesis and flavonoid accumulation in leaves of Hedyotis corymbosa (L.) Lam.
}

\author{
Anh Tuan Le ${ }^{1}$, Ngo Hoang Phan ${ }^{2} \&$ Thuong Kiet Do ${ }^{1,2^{*}}$ \\ ${ }^{1}$ Research Center for Hi-Tech in Agriculture Applications, University of Science, Viet Nam National University, Linh Trung, Thu Duc District, \\ 71308 Ho Chi Minh City, Vietnam \\ ${ }^{2}$ Department of Plant Physiology, Faculty of Biology and Biotechnology, University of Science, Viet Nam National University, 227 Nguyen Van \\ Cu Street, Ward 4, District 5, 72711 Ho Chi Minh City, Vietnam \\ *Email:dtkiet@hcmus.edu.vn
}

\section{ARTICLE HISTORY}

Received: 28 April 2021

Accepted: 25 September 2021

Available online: 20 October 2021

\section{KEYWORDS}

Chlorophyll Fluorescence

Electron Transport Rate

LED - Light-Emitting Diode

Photosynthesis

Flavonoids

Non-Photochemical Quenching

\begin{abstract}
In plants, blue light with a short wavelength can promote light reaction in photosynthesis and increase dry mass. Photosynthesis plays an important role in supporting carbohydrates for primary and secondary metabolism processes. Flavonoids are phenolic compounds, a class of plant secondary metabolites, that can be obtained from many medicinal herbs. These phenolic compounds are involved in the reactive oxygen species scavenging system, inhibit lipid peroxidation by free-radical, chelate redox-active metals resulting in their antioxidant ability and cardioprotective effects. In this study, $\mathrm{H}$. corymbosa (L.) Lam., one of the common medicinal herbs, was cultured for 4 weeks under conditions of $450 \mathrm{~nm}$ blue LED (light-emitting diode) lights at the different light intensity as treatments and fluorescent lamp light as a control to investigate the effects of blue light on photosynthesis and flavonoid accumulation in leaves. The results show that blue light at $450 \mathrm{~nm}$ promoted photosynthetic rate by enhancing stomatal opening, electron transport rate in light reaction. Blue light also enhanced photoprotection by decrease the quantum yield of non-photochemical losses, increase the quantum yield of non-photochemical quenching and gained $24 \%$ more in dry mass. The accumulation of flavonoid and total phenolic compounds in leaves was followed by a decrease in sucrose. These events proved that blue light enhances photosynthesis and increase carbohydrate and flavonoid accumulation in leaves.
\end{abstract}

\section{Introduction}

Herbs or medicinal plants are widely used around the world. Those plants have many antioxidant compounds such as polyphenols. Among them, flavonoids are a large variant of phenolic with antioxidant activity (1). These molecules are capable to scavenge the ROS (Reactive oxygen species) of plant cells that are produced from photosynthesis and cause a potential risk of photodamage. Plants often receive excess light and ultraviolet radiation from sunlight so these lead to increased production of ROS, which may cause photooxidative damage. Plants have evolved protective and response mechanisms against photodamage. ROS act as signaling molecules that mediate vital functions in inducing resistance to light stress and other abiotic and biotic stresses (2-4).

Leafy vegetables contain lower polyphenols when grown in a greenhouse without additional light than when grown in the field (5). Flavonoid accumulation is light-dependent and its rate of biosynthesis is related to light intensity $(6,7)$ UV-B $(280-315 \mathrm{~nm})$ and PAR (400-700 nm) applied in the cultivation of some medicinal plants obtained higher polyphenol content than the control. Light with strong energy levels such as blue light and UV light has a stronger effect than other PAR wavelengths $(8,9)$. The plant receives UV and blue light by using phototropin, cryptochrome and UVR8 to initiate the anti-oxidation system $(4,10)$.

To carry out such studies, light sources that are easy to control with wavelengths such as LEDs (Lightemitting diodes) are used (11). Previous studies have shown that blue LED causes stomatal opening (10), increases the transpiration rate of leaves and photosynthetic rate $(12,13)$. When treated with blue light for 12 days, plant biomass and chlorophyll content were lower when compared to red and white light conditions (13). Blue light not only affects flavonoid accumulation but also affects the pigments that aid in the nonphotochemical quenching in plants' photosynthesis. The carotenoids involved in the xanthophyll cycle such as violaxanthin and

(c) Le et al (2021). This is an open-access article distributed under the terms of the Creative Commons Attribution License, which permits unrestricted use, distribution and reproduction in any medium, provided the original author and source are credited (https://creativecommons.org/licenses/by/4.0/). 
zeaxanthin increased in plants that received blue light (14).

Chlorophyll fluorescence measurements have been proven to be a good probe of photosynthesis in vivo and a powerful method to detect various stress effects by environmental changes (15). There are many useful parameters like yields of photochemistry (Y(II)), light-regulated (Y(NPQ)), and non-regulated (Y(NO)) heat dissipation through non-photochemical quenching to analyze plant stress conditions (15-18).

$H$. corymbosa (L.) Lam. is a medicinal plant with a high content of phenolic compounds and is widely used in traditional medicine (19). In previous studies, increasing light intensity to $150 \mu \mathrm{mol} . \mathrm{m}^{-2} . \mathrm{s}^{-1}$ reduced dry biomass but increased the accumulation of secondary compounds of in vitro plants (20). In this study, we used $450 \mathrm{~nm}$ LED light as an artificial light source, to investigate the effect of blue light on photosynthesis and phenolic accumulation in the leaves of this herb, to improve farming methods and increase beneficial secondary compounds in this plant.

\section{Materials and Methods}

\section{Plant material}

Seeds of $H$. corymbosa (L.) Lam. were collected in the wasteland in Ho Chi Minh City, Vietnam. Ten-day-old in vitro plants of $H$. corymbosa with two pairs of true leaves grown from seeds on MS medium (21) with 30 $\mathrm{g} / \mathrm{L}$ sugar. The $\mathrm{pH}$ of the medium was adjusted to 5.8 before jellying the medium with $6 \mathrm{~g} / \mathrm{L}$ agar. The cultures were placed under $50 \mu \mathrm{mol} . \mathrm{m}^{-2} \cdot \mathrm{s}^{-1}$ white fluorescent light (12-12 photoperiod) at $27 \pm 2{ }^{\circ} \mathrm{C}$ and relative humidity of $65 \pm 5 \%$. Ten-day-old ex vitro plants with two pairs of true leaves, growing from seed on clean soil and cow manure (ratio 3:1). Plants were grown in a greenhouse under $450 \pm 100$ $\mu \mathrm{mol} . \mathrm{m}^{-2} . \mathrm{s}^{-1}$ sunlight, at $32 \pm 2{ }^{\circ} \mathrm{C}$ and relative humidity of $70 \pm 5 \%$.

\section{Blue light treatment}

In vitro plant materials were incubated in a growth room for 4 weeks under $450 \mathrm{~nm}$ blue LEDs (LAFTRC, Korean) and $36 \mathrm{~W}$ fluorescent lamps (OSRAM, Korea) as a control light source with a 12-12 photoperiod. The photosynthetic photon flux density (PPFD) was controlled at $50 \mu \mathrm{mol} . \mathrm{m}^{-2} . \mathrm{s}^{-1}$ for the control light source and at 4 different intensities (25, 50, 100 and $150 \mu \mathrm{mol} . \mathrm{m}^{-2} . \mathrm{s}^{-1}$ ) for the $450 \mathrm{~nm}$ LED. Light intensity was measured by LI-250A - LI-190R Quantum Sensor (LI-COR Inc., Nebraska, USA). This experiment was set up at the LED Agri-bio Fusion Technology Research Center (LAFTRC), Chonbuk National University, Republic of Korea.

Ex vitro plants were incubated for 4 weeks under $450 \mathrm{~nm}$ blue LEDs (LAFTRC, Korean) and $40 \mathrm{~W}$ fluorescent lamps (Philips, Netherlands) as a control light source with a 12-12 photoperiod. All light conditions were controlled at $100 \mu \mathrm{mol} . \mathrm{m}^{-2} . \mathrm{s}^{-1}$. This experiment was set up at the Research Center for HiTech in Agriculture Applications (RCHAA), University of Science, VNU-HCM, Vietnam.

\section{Growth parameter measurements}

Plant height was measured every week during treatment. After 4 weeks of the treatment plant materials were harvested for fresh weight (FW), and then plants were dried to a constant weight at $80{ }^{\circ} \mathrm{C}$ for measuring dry weights (DW).

\section{Measurements of chlorophyll fluorescence parameters}

The fifth leaves were dark-adapted for at least $15 \mathrm{~min}$ before measurement by using dark leaf clips DLC-8. Chlorophyll fluorescence parameters such as the quantum efficiency of PSII (Y(II)), the nonphotochemical quenching (NPQ), the quantum yield of the down-regulatory non-photochemical quenching (Y(NPQ)), the quantum yield of other nonphotochemical losses (Y(NO)), an estimate of the fraction of open PSII centers (qL), and the electron transport rate (ETR) under $0-2000 \mu \mathrm{mol} . \mathrm{m}^{-2} . \mathrm{s}^{-1} \mathrm{using}$ the portable fluorometer PAM 2500 (Walz, Effeltrich, Germany) operated by PAM software.

\section{Measurements of chlorophyll and total carotenoids content}

Leaf sample of $0.5 \mathrm{~g}$ was isolated and extracted with acetone (80\%). The optical density of the extract was measured at wavelengths 470, 663 and $646 \mathrm{~nm}$ by using Genesys 30 spectrophotometer (Thermo Scientific, USA). Chlorophyll a, b and total carotenoids (mg. $\mathrm{g}^{-1}$ fresh weight) were calculated according to the description of Wellburn (1994) (22).

\section{Measurements of photosynthetic rate}

The net photosynthetic rate of the pair of the fifth leaves was measured by oxygen electrode with the LD2 electrode chamber of the Leaf Lab 2 system (Hansatech, United Kingdom). The leaf chamber temperature was controlled at $27 \pm 1{ }^{\circ} \mathrm{C}$, light source during measurements of gas exchange parameters of each treatment was controlled at $50 \mu \mathrm{mol} . \mathrm{m}^{-2} . \mathrm{s}^{-1}$. The net photosynthetic rate of the sample was calculated based on the amount of oxygen released in the leaf chamber $\left(\mu \mathrm{mol} \mathrm{O} 2 \cdot \mathrm{m}^{-2} \cdot \mathrm{s}^{-1}\right)$.

\section{Measurements of stomatal aperture}

The leaves were swept onto the underside with a cyanoacrylate glue (mixed in toluene and ethyl acetate solvents) and fixed on the slide. The surface of the leaf with the stomata was printed on the cyanoacrylate film. The cyanoacrylate film was photographed by CKX41 inverted microscope (Olympus, Japan) with DFC 450 camera (Leica, German) and the stomatal aperture was measure by the Image program (Wayne Rasband, imagej.net).

\section{Extract and determine total sugar and starch content}

The leaf samples were ground in absolute ethanol, centrifuged, and the supernatant (supernatant 1) was collected. The residue was hydrolyzed by perchloric acid, centrifuged, and the supernatant (supernatant 2) was also collected. the optical density of the mixture of the two supernatants (separately) with phenol and sulphuric acid was measured. The extraction and determination of total sugar and starch content were carried out by following standard procedure (23). 


\section{Extract and determine total phenolic and flavonoid}

The total phenolic in the leaves was determined by the Folin-Ciocalteu method according to the principle of the reduction of the Folin-Ciocalteu reagent by the phenol compound in an alkaline medium and the resulting color product. The phenolic content (mg.g ${ }^{-1}$ fresh weight) was calculated by optical density at 765 $\mathrm{nm}$ and the gallic acid calibration curve. The total flavonoid content in the leaves was determined by the aluminium chloride colorimetric method. The total flavonoid content (mg. ${ }^{-1}$ fresh weight) was calculated by optical density at $510 \mathrm{~nm}$ and the rutin calibration curve (24).

\section{Statistical analysis}

All experiments have 6 replications per treatment. The data recorded from the experiments were statistically processed using SPSS 11.5 for Windows. Statistical significance was estimated at $\mathrm{P}<0.05$ according to $\mathrm{T}$ Test and Duncan's multiple range test with one-way ANOVA. All data were given as mean \pm SE.

\section{Results}

\section{Effects of blue light on in vitro plant growth}

In the fourth week of treatment, the fresh and dry weights of in vitro plants illuminated with a $450 \mathrm{~nm}$ blue LED light source reached the highest values at the light intensity of $50 \mu \mathrm{mol} . \mathrm{m}^{-2} . \mathrm{s}^{-1}$ but reduced at higher light intensities at 100 and $150 \mu \mathrm{mol} . \mathrm{m}^{-2} . \mathrm{s}^{-1}$ (Fig. 2). Plants grew under blue light at $50 \mu \mathrm{mol} \cdot \mathrm{m}^{-2} \cdot \mathrm{s}^{-1}$ produced and developed new branches while leaves of the plants treated at $150 \mu \mathrm{mol} . \mathrm{m}^{-2} . \mathrm{s}^{-1}$ became yellow (Fig. 1). In the comparison with plants

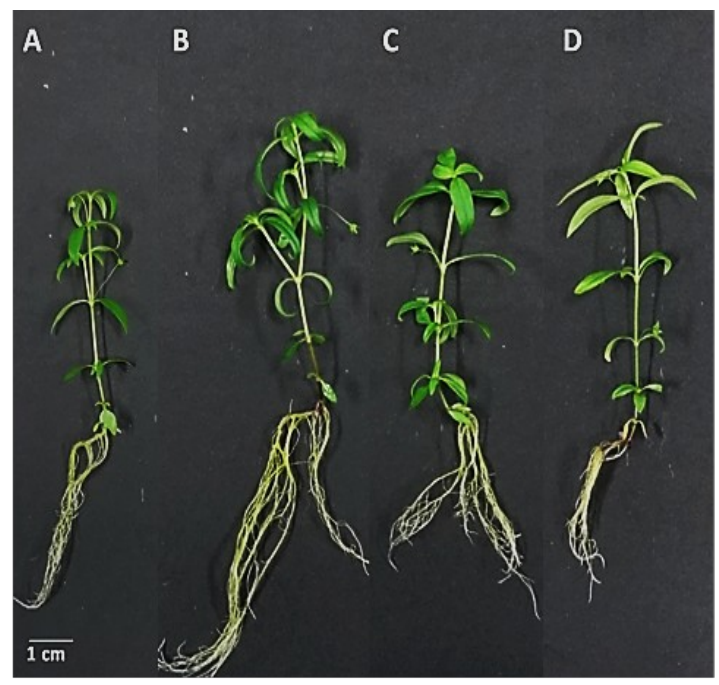

Fig. 1. In vitro $H$. corymbosa plants after 4 weeks of growth under blue LED light at 25 (A), 50 (B), 100 (C), 150 (D) $\mu \mathrm{mol} . \mathrm{m}^{-2} . \mathrm{s}^{-1}$.

illuminated with control light at the same 50 $\mu \mathrm{mol} . \mathrm{m}^{-2} . \mathrm{s}^{-1}$ in PPFD, the height of blue light treated plants began to be $17 \%$ lower in the third week of treatment. In contrast, the fresh and dry weight of these treated plants increased by $38 \%$ compared to the control plants. Statistically significant differences in plant height began to occur in the third week, while biomass changes were only different at week 4 , especially dry weight (Fig. 2).

\section{Effects of blue light on fluorescence parameters of leaves}

In vitro leaves of $H$. corymbosa plants 4 weeks treated with the blue light at low PPFD (25 and 50 $\left.\mu \mathrm{mol} . \mathrm{m}^{-2} \cdot \mathrm{s}^{-1}\right)$, the maximum quantum yield of PSII (Y(II)) remained very low (same as control plant) while exposing to $2000 \mu \mathrm{mol} . \mathrm{m}^{-2} \cdot \mathrm{s}^{-1}$. But those plants treated with higher PPFD blue light (100 and 150 $\mu$ mol. $\mathrm{m}^{-2} . \mathrm{s}^{-1}$ ) could hold $2-3 \%$ of Y(II). The estimate of the fraction of open PSII centers (qP) of 100 and 150 $\mu \mathrm{mol} . \mathrm{m}^{-2} . \mathrm{s}^{-1}$ blue-light-treated plants higher than the control plant while the non-photochemical fluorescence quenching coefficient $(\mathrm{qN})$ of all treated plants were significantly higher than control plants. The quantum yield of the down-regulatory nonphotochemical quenching ( $\mathrm{Y}(\mathrm{NPQ}))$ increased and the quantum yield of other non-photochemical losses (Y(NO)) decreased in all blue light treated plants. The intensity of blue light treated on the plants was proportional to the increase in post-treatment relative electron transfer rate (ETR). Only plants treated with 100 and $150 \mu \mathrm{mol} \cdot \mathrm{m}^{-2} \cdot \mathrm{s}^{-1}$ maintained ETR at the highest rate under $1000 \mu \mathrm{mol} \cdot \mathrm{m}^{-2} \cdot \mathrm{s}^{-1}$. At 2000 $\mu \mathrm{mol} . \mathrm{m}^{-2} \cdot \mathrm{s}^{-1}$ the $150 \mu \mathrm{mol} . \mathrm{m}^{-2} \cdot \mathrm{s}^{-1}$ treated plants still kept ETR stable (Fig. 3).

Effects of blue light on photosynthesis, photosynthetic product and flavonoid content of $e x$ vitro plant

Ex vitro $H$. corymbosa after 4 weeks treated with blue light at $100 \mu \mathrm{mol} \cdot \mathrm{m}^{-2} \cdot \mathrm{s}^{-1}$, has lower chlorophyll b content in leaves than plants grown under fluorescent lighting. Concentrations of chlorophyll a as well as carotenoid in leaves were not different from the control (Fig. 4). Treated plants had higher stomatal aperture and photosynthetic rates than untreated plants (Fig. 5 and Table 1). The fresh and dry weight of the treated plant is nearly $20 \%$ higher than the control plant (Fig. 2). The 4-week treatment plant in growth room conditions decreased sucrose but increased the starch, phenolic and flavonoid content of the leaves (Table 2).

\section{Discussion}

\section{The effects of blue light in different growing} conditions

Mature leaves of sun plants grown in low PPFD and have not been adapted to strong light could not be able to increase light-saturated photosynthetic capacity when they were exposed to higher PPFD and might suffer photooxidative bleaching and cell death. However, young leaves developing after transfer to the high PPFD do not exhibit photoinhibition when became mature (25). H. corymbosa had the same problem. In vitro plants grown under low light at 50 $\mu \mathrm{mol} . \mathrm{m}^{-2} \cdot \mathrm{s}^{-1}$ for the first 10 days continued to grow at $50 \mu \mathrm{mol} . \mathrm{m}^{-2} . \mathrm{s}^{-1}$ better at higher light levels such as 100 and $150 \mu \mathrm{mol} . \mathrm{m}^{-2} . \mathrm{s}^{-1}$ (Fig. 2). Whereas the ex vitro plants adapted for the first 10 days with 450 $\mu \mathrm{mol} . \mathrm{m}^{-2} . \mathrm{s}^{-1}$ grew well at $100 \mu \mathrm{mol} . \mathrm{m}^{-2} . \mathrm{s}^{-1}$ over the next 4 weeks (Fig. 6). Those confirm that the plant 

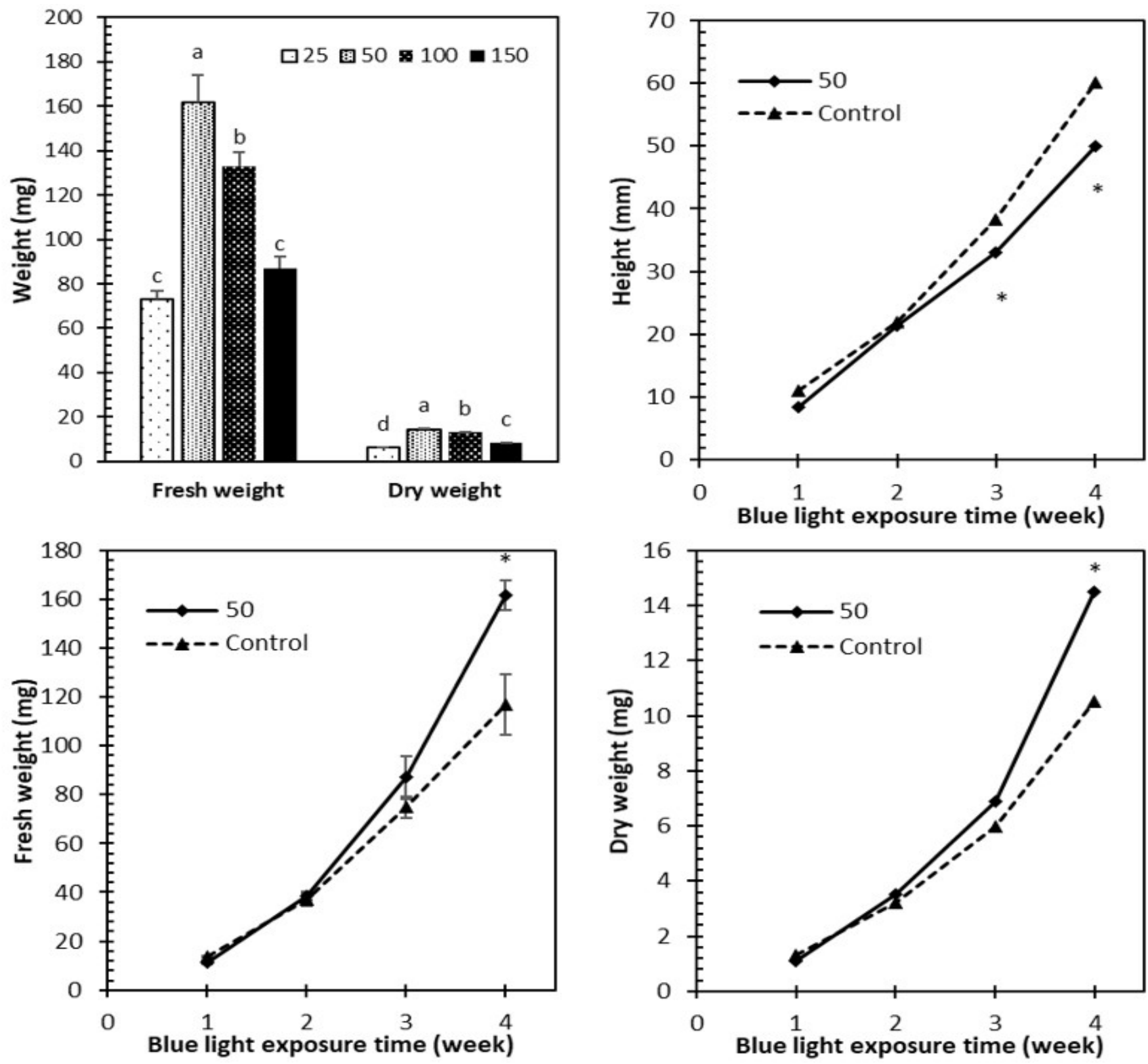

Fig. 2. Fresh and dry weight of in vitro $H$. corymbosa plants after 4 weeks of growth under blue LED and white fluorescent light (control) at $50 \mu \mathrm{mol} . \mathrm{m}^{-2} \cdot \mathrm{s}^{-1}$. Means $( \pm \mathrm{SE}$ ) significantly different between cases and control via T-test at $\mathrm{p} \leq 0.05$ (1-way ANOVA, $\mathrm{n}=6$ ).

responds to an increase in light intensity similar to that of a sun plant. Whether the seedlings were adapted to low or high light intensity, there is also a pattern of response to blue light, the increase in biomass compared to the control.

Besides, under the condition of blue light at high intensity, in vitro plants tended to not branch and had a lighter green leaf color (Fig. 1). This corresponds to a decrease in chlorophyll content $\mathrm{b}$ in ex vitro leaves (Fig. 4). Chlorophyll b is present on the peripheral antenna proteins of higher plants' photosynthesis system, which is responsible for collecting light and transferring energy to the reaction center. The amount of outermost antenna protein is lower in low light compared to strong lighting conditions (26). The strong light condition also leads to a decrease in chlorophyll b biosynthesis from chlorophyll a through the enzyme CAO (chlorophyllide a oxygenase) (27). And this explains why the same things happened in $H$. corymbosa, but the different thing was that the effect of high light intensity could be replaced by blue light even at a lower light intensity in ex vitro culture (Fig. 4). Thus it can be concluded that blue light causes a decrease in chlorophyll $\mathrm{b}$ at the 100 and 150 $\mu \mathrm{mol} . \mathrm{m}^{-2} \cdot \mathrm{s}^{-1}$, not related to a change in light intensity from low to high or from high to low. Blue light acts as an environmental signal and is picked up and reacted by the plant by modifying its photosynthetic system to this new condition. But in the case of $H$. corymbosa, the lighting conditions for the first 10 days as a pretreated condition, determined their ability to respond to the high intensity of blue light.

\section{Blue-light-induced photoprotection in $\boldsymbol{H}$. corymbosa}

By using modern PAM fluorometers, the quantum yields of photochemical and non-photochemical energy conversion in PS II ( $\phi \mathrm{II}, \phi N \mathrm{NQ}, \phi N O)$ are calculated with Saturation Pulse and displayed as the 
parameters $\mathrm{Y}(\mathrm{II}), \mathrm{Y}(\mathrm{NPQ})$ and $\mathrm{Y}(\mathrm{NO})$, the sum of which is always unity: $\mathrm{Y}(\mathrm{II})+\mathrm{Y}(\mathrm{NPQ})+\mathrm{Y}(\mathrm{NO})=1 . \quad \mathrm{Y}(\mathrm{II})$ corresponds to the photochemical fraction of energy conversion in PSII, so 1 - Y(II) corresponds to the total quantum yield of the two-loss processes, $\mathrm{Y}(\mathrm{NO})$ and $\mathrm{Y}(\mathrm{NPQ})(11,12)$.

$H$. corymbosa leaves treated with blue light at any light intensity from 25 to $150 \mu \mathrm{mol} . \mathrm{m}^{-2} . \mathrm{s}^{-1}$ for 4 weeks had Y(NO) parameter under of were $24 \%$ lower than control leaves (Fig. 3). Y(NO) reflects the fraction of energy that is passively dissipated due to closed PSII

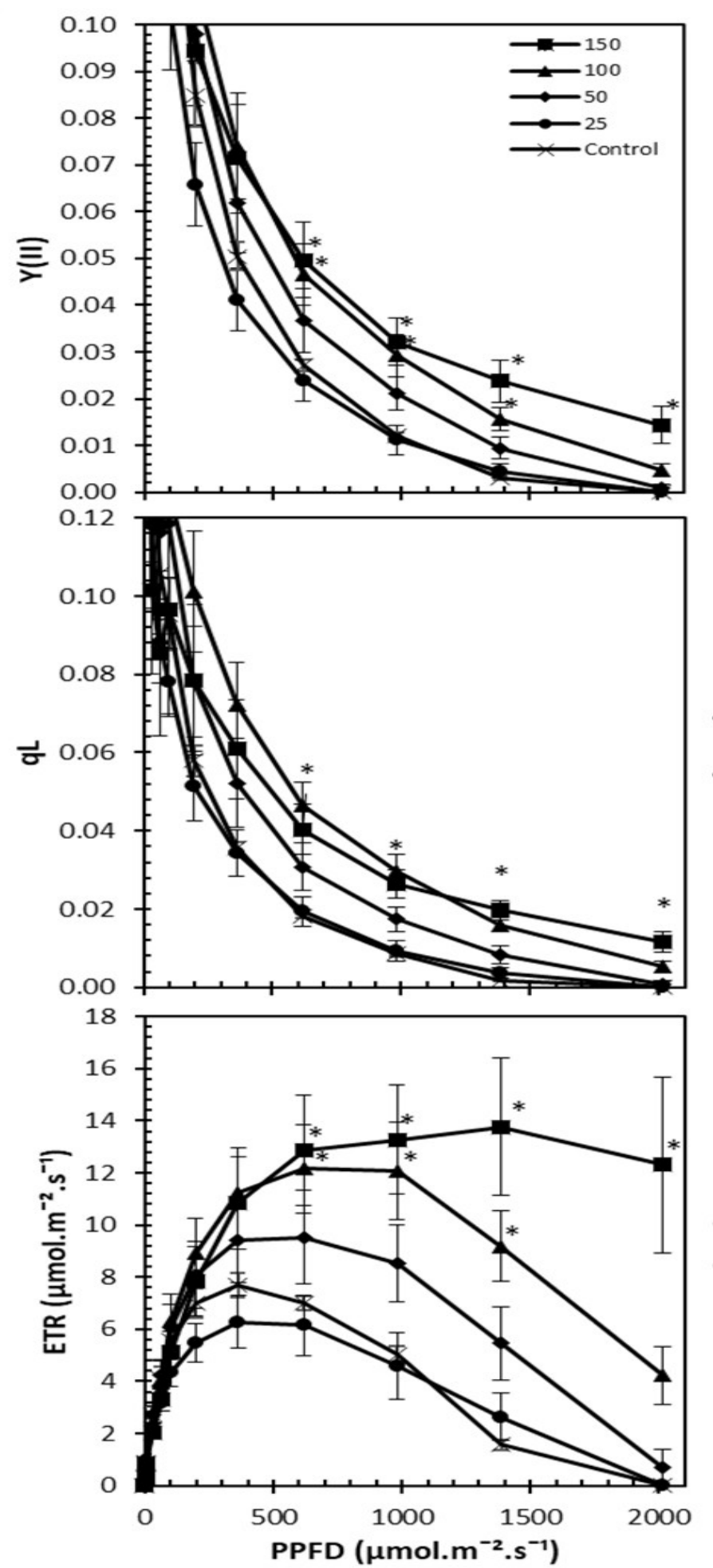

reaction centers (11). This means that the blue-lighttreated leaves have a higher number of opened PSII reaction centers ( $q L$ parameter) than the control. But only the qL parameter of leaves treated with highintensity blue light (100 and $150 \mu \mathrm{mol} . \mathrm{m}^{-2} . \mathrm{s}^{-1}$ ) was significantly higher (nearly 3 times) than the control when exposed to high light conditions at over 500 $\mu \mathrm{mol} . \mathrm{m}^{-2} . \mathrm{s}^{-1}$ PPFD. treatment with high-intensity blue light also increased Y(II) of leaf and led to the enhancement and maintaining the stability of the electron transport rate (ETR) even when the leaves

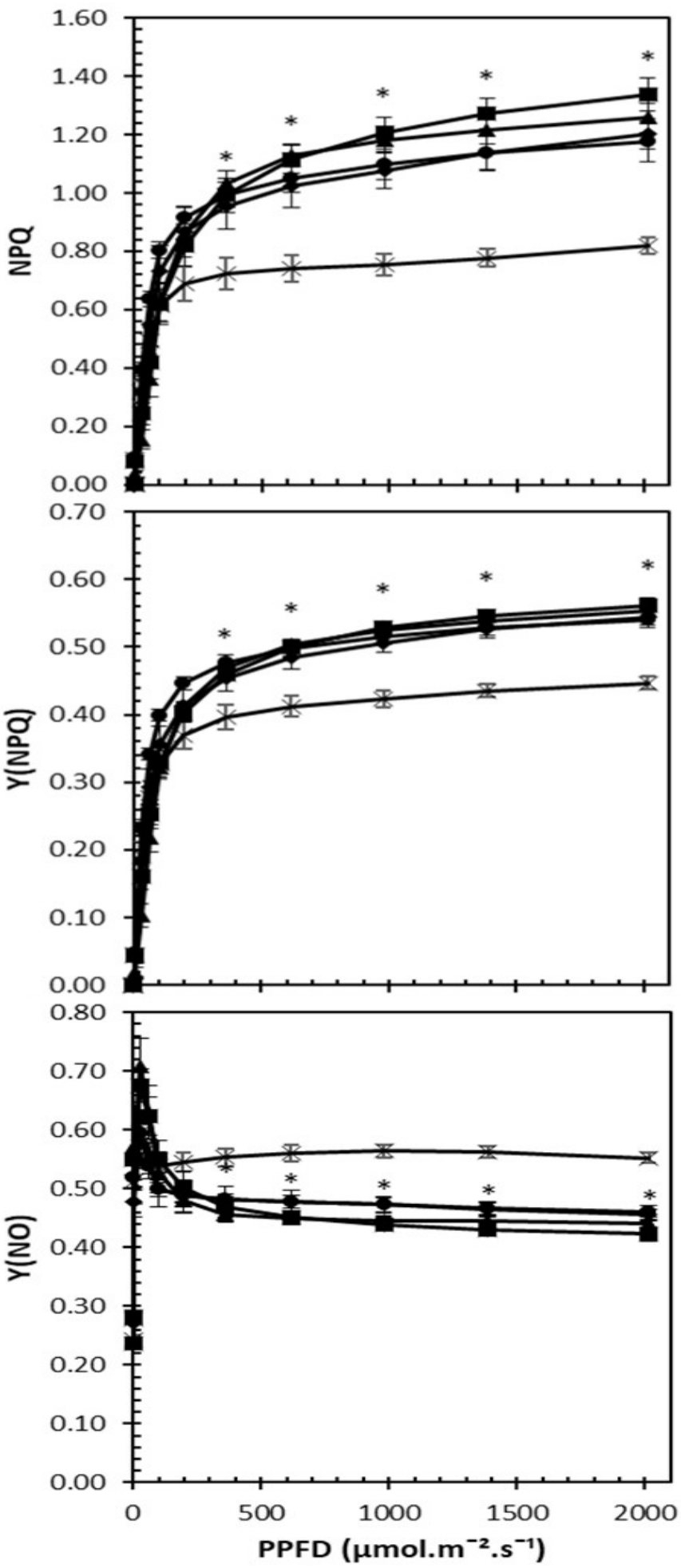

Fig. 3. Chlorophyll fluorescence parameters Y(II), qL, ETR, NPQ, Y(NPQ), Y(NO) of the H. corymbosa in vitro leaf after 4 weeks of growth under blue LED light at 25, 50, 100, $150 \mu \mathrm{mol} \cdot \mathrm{m}^{-2} \cdot \mathrm{s}^{-1}$ and white fluorescent light (control). Means $( \pm$ SE) significantly different between cases and control via T-test at $\mathrm{p} \leq 0.05$ (1-way ANOVA, $n=6$ ). 
were exposed to $2000 \mu \mathrm{mol} . \mathrm{m}^{-2} . \mathrm{s}^{-1}$ PPFD. Moreover, the NPQ value of the treated leaves was also over $60 \%$ higher than that of the control leaves (Fig. 3). The high values of $\mathrm{Y}(\mathrm{NPQ})$ and the low values of $\mathrm{Y}(\mathrm{NO})$ are indicative of the high photoprotective capacity of a plant to protect itself against damage by excess illumination (11). Thus, blue light is an effective exogenous signal that helps $H$. corymbosa activate its self-defense system against photo-inhibition by promoting the ETR in the light reaction of photosynthesis.

\section{The relation between photosynthesis and flavonoid accumulation under blue light condition}

Phenolic and flavonoid compounds are wide widely distributed phytochemicals in most higher plants and are associated with plant defense systems against abiotic and biotic stress, including UV exposure, high

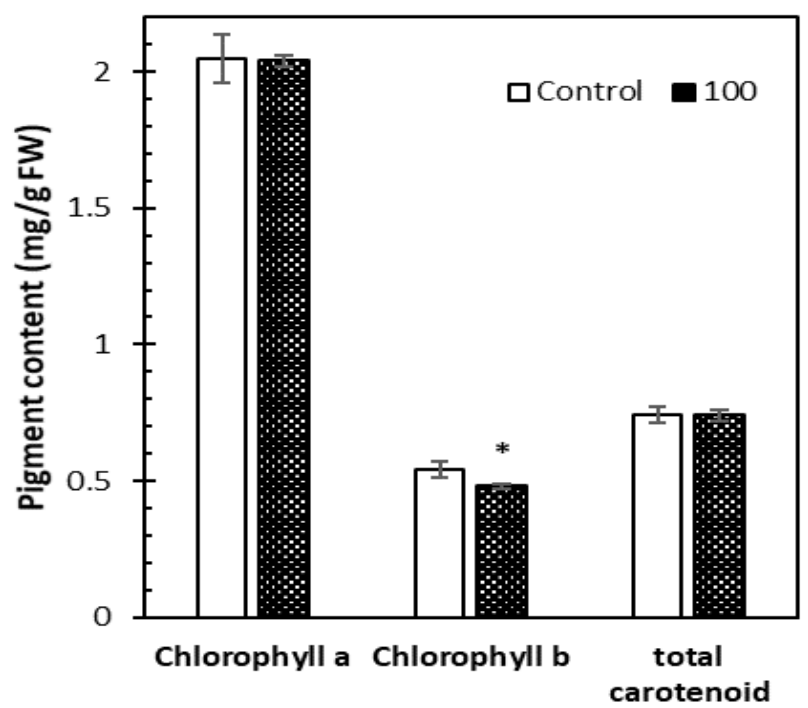

Fig. 4. Chlorophyll (Chl) a and b, carotenoids (Car) content of leaves after 4 weeks of growth under blue LED and white fluorescent light (control) at $100 \mu \mathrm{mol} . \mathrm{m}^{-2} . \mathrm{s}^{-1}$. Means $( \pm \mathrm{SE})$ significantly different between cases and control via T-test at $p \leq 0.05$ (1-way ANOVA, $n=6$ ). temperature, under extreme light and wounding. Blue LED light has a pronounced effect on the accumulation of phenolic and flavonoid metabolites. For instance, there are observations on an increase of total phenolic compound in Lettuce at both treatments in a short- and long-day duration under blue LED light to compare with white light (28). In numerous previous studies, the same trend was recorded in Brassica napus L., Lactuca sativa, Ocimum basilicum, Rhodiola imbricata when the plants were exposed under blue LED with light intensity from 50 to 200 umol.m ${ }^{-2} . \mathrm{s}^{-1}$ (19, 29-32). Furthermore, increased total flavonoid content was reported in different plants irradiated with additional blue LED light, even though the blue LED has been applied, only or combine with another light wavelength, as supplemental light (19, 29-32). Our result was showed the total phenolic content of the treated leaves of $H$. corymbosa increased by $21 \%$, of which, flavonoids increased by $117 \%$. Flavonoids, which accounted for $78 \%$ of the total phenolic, were higher in the Blue-light-treated leaves than in the control plants (43\%). In several studies have reported the phenylalanine ammonialyase (PAL) is the key role of LEDs in phenolic biosynthesis in plants $(28,30)$. Additionally, the positive correlation between flavonoid accumulation and synthesis-related gene expression, encodings flavonoid synthesis-related enzymes, such as phenylalanine ammonia-lyase (PAL), chalcone synthase (CHS), CHI and flavanols synthase, in Anoectochilus roxburghii was recorded (33).

Light is a key factor that affects phytochemical synthesis, which was the source of primary and secondary product accumulation in most of the plants (34). As discussed above, blue light promoted the light reaction of photosynthesis, increased the stomata opening thereby facilitating gas exchange, provided the Calvin cycle for $\mathrm{CO}_{2}$ fixation. However, plant biomass is achieved largely due to the accumulation of starch in the leaves. On the other hand, blue light is a signal that causes leaf stomatal opening, chloroplast accumulation leaf expansion and leaf movement.
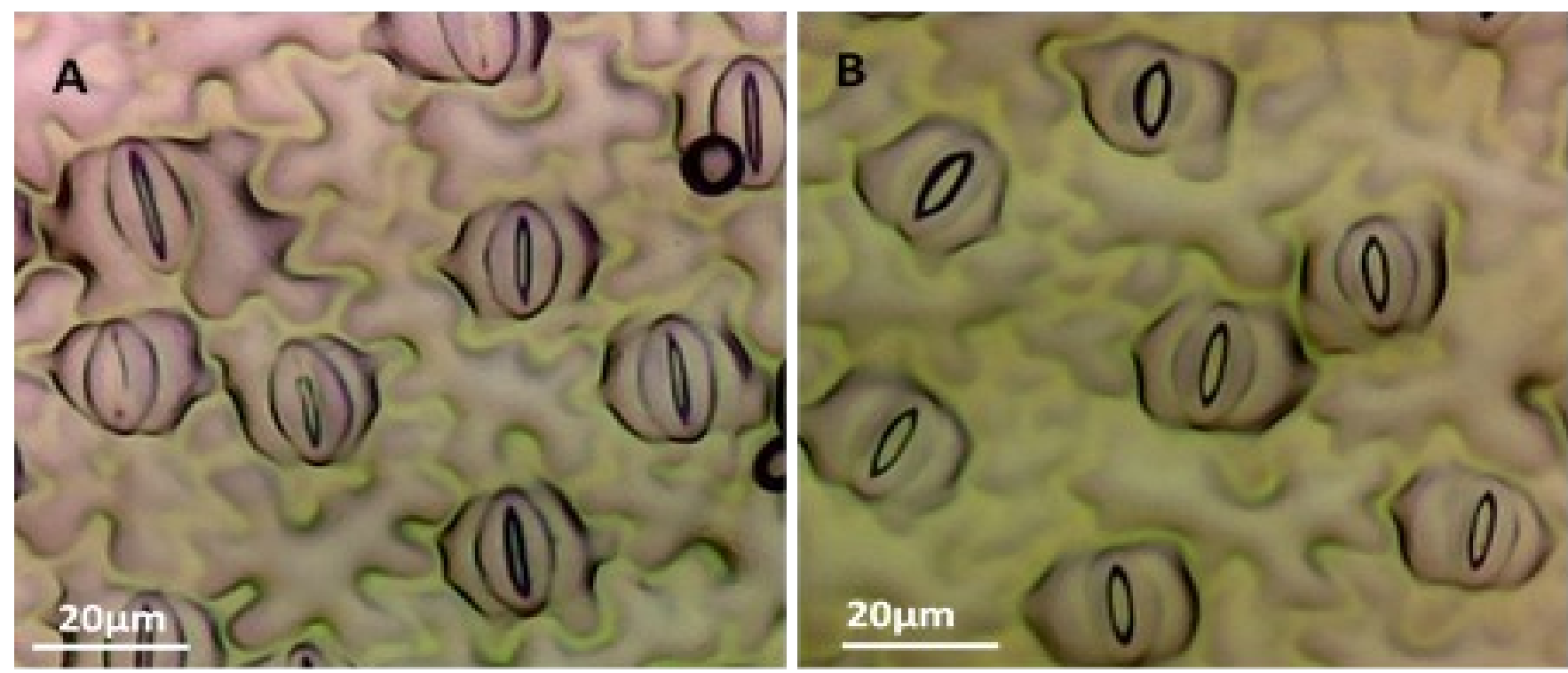

Fig. 5. Stomatal of $H$. corymbosa leaves after 4 weeks of growth under white fluorescent (control with normal stomatal aperture, A) and blue LED (wide open stomatal, B) light at $100 \mu \mathrm{mol} . \mathrm{m}^{-2} . \mathrm{s}^{-1}$. 
Phototropin 1 and 2 are blue light receptors that regulate those responses (10). In blue light condition at $100 \mu \mathrm{mol} . \mathrm{m}^{-2} . \mathrm{s}^{-1}$ the ex vitro leaves had the increase of stomatal opening $(\approx 27 \%)$, net photosynthetic rate $(\approx 39$ \%) (Fig. 5 and Table 1 ) and starch content ( $\approx 27 \%)$. This increase led to the gain of fresh weight (18\%) and dry weight (24\%) (Fig. 2).

Similar to the photosynthetic rate, the respiratory rate also increased sharply (50\%) (Table 2). Thus the leaf cells will also receive 50\% more energy and perhaps this extra energy helps the leaves synthesize

Table 1. Stomatal aperture, photosynthesis and respiratory rate in leaves of Hedyotis corymbosa after 4 weeks of growth under blue LED and white fluorescent light (control) at $100 \mu \mathrm{mol} . \mathrm{m}^{-2} . \mathrm{s}^{-1}$. Means $( \pm \mathrm{SE})$ significantly different between cases and control via T-test at $\mathrm{p}$ $\leq 0.05$ (1-way ANOVA, $n=6$ ).

\begin{tabular}{|c|c|c|c|}
\hline $\begin{array}{l}\text { Light } \\
\text { treatment }\end{array}$ & $\begin{array}{c}\text { Stomatal } \\
\text { aperture }(\mu \mathrm{m})\end{array}$ & $\begin{array}{l}\text { photosynthetic } \\
\text { rate }\left(\mu \mathrm{mol}^{-}\right. \\
\left.\mathrm{O}_{2} \cdot \mathrm{cm}^{-2} \cdot \mathrm{min}^{-1}\right)\end{array}$ & $\begin{array}{c}\text { respiratory rate } \\
\underset{(\mu \mathrm{mol}}{\left.\mathrm{O}_{2} \cdot \mathrm{cm}^{-2} \cdot \mathrm{min}^{-1}\right)}\end{array}$ \\
\hline Control & $3.30 \pm 0.08$ & $0.138 \pm 0.010$ & $0.145 \pm 0.02$ \\
\hline Blue LED & $4.22 \pm 0.17 *$ & $0.192 \pm 0.016 *$ & $0.219 \pm 0.02 *$ \\
\hline
\end{tabular}

Table 2. Sucrose, starch, total phenolic and total flavonoid content of $H$. corymbosa leaves after 4 weeks of growth under white fluorescent (control) and blue LED light at $100 \mu \mathrm{mol} \cdot \mathrm{m}^{-2} \cdot \mathrm{s}^{-1}$. Means $( \pm S E)$ significantly different between cases and control via T-test at $p$ $\leq 0.05$ (1-way ANOVA, $n=6$ ).

\begin{tabular}{|c|c|c|c|c|}
\hline \multirow{2}{*}{$\begin{array}{c}\text { Light } \\
\text { treatment }\end{array}$} & \multicolumn{4}{|c|}{ Content (mg.g $\left.{ }^{-1} \mathrm{FW}\right)$} \\
\hline & Sucrose & Starch & $\begin{array}{c}\text { Total } \\
\text { phenolic }\end{array}$ & $\begin{array}{c}\text { Total } \\
\text { flavonoid }\end{array}$ \\
\hline Control & $25.85 \pm 3.64 *$ & $80.01 \pm 5.45$ & $1.56 \pm 0.07$ & $0.68 \pm 0.06$ \\
\hline Blue LED & $18.38 \pm 1.08$ & $101.31 \pm 6.56 *$ & $1.90 \pm 0.08 *$ & $1.48 \pm 0.30 *$ \\
\hline
\end{tabular}

large amounts of antioxidant compounds. Indeed, the increase in the respiratory rate came with a decrease in total sucrose content (by 29\%). This means that sucrose has been used to create glucose for respiration and thus the leaf cells will have additional precursors available for other secondary metabolic activities. Indeed, the total phenolic content of the treated leaves of $H$. corymbosa increased by $21 \%$, of which, flavonoids increased by $117 \%$. Flavonoids, which accounted for $78 \%$ of the total phenolic, were higher in the Blue-light-treated leaves than in the control plants $(43 \%)$. Our research confirms that pretreatment with strong light intensity helps plants respond to $450 \mathrm{~nm}$ LED blue light better and therefore increases herbs flavonoid accumulation.

\section{Conclusion}

$450 \mathrm{~nm}$ blue LED light promotes photoprotection through increasing $\mathrm{Y}(\mathrm{NPQ})$, lowering $\mathrm{Y}$ (NO), enhancing $\mathrm{Y}$ (II), $\mathrm{qL}$ and maintaining ETR, thus increasing biomass of $H$. corymbosa (L.) Lam. under both in vitro and ex vitro culture conditions.

In vitro plants pretreated with $50 \mu \mathrm{mol} . \mathrm{m}^{-2} . \mathrm{s}^{-1}$ light could not grow properly at 100 and 150 $\mu \mathrm{mol} . \mathrm{m}^{-2} . \mathrm{s}^{-1}$ and tended to yellowing. Ex vitro plants pretreated with $450 \mu \mathrm{mol} . \mathrm{m}^{-2} . \mathrm{s}^{-1}$ well adapted to blue light treatment at $100 \mu \mathrm{mol} \cdot \mathrm{m}^{-2} \cdot \mathrm{s}^{-1}$ and had an increase in stomatal aperture and gas exchange rate resulting in a strong accumulation of both starch and flavonoid.

\section{Acknowledgements}

This research was supported by a grant from the Vietnam National University, Ho Chi Minh City, Vietnam (Project No. C2017-18-13). We are also grateful to the Research Center for High-Tech Application in Agriculture; Laboratory of Plant Physiology, Department of Plant Physiology, Faculty of Biology and Biotechnology, University of Sciences, VNU-HCM and LED Agri-bio Fusion Technology Research Center, Chonbuk National University for providing the experimental facilities. Special thanks to Prof. Chang-Hee Hong, Dr. Seon-ki Kim and Dr. KyuHan Lee for supporting the research at Chonbuk National University.

\section{Authors' contributions}

ATL carried out the whole study and drafted the manuscript under the supervision of TKD and NHP. All authors read and approved the final manuscript.

\section{Compliance with ethical standards}

Conflict of interest: Authors do not have any conflict of interests to declare.

Ethical issues: None.

\section{References}

1. Okuda T. Antioxidants in herbs: polyphenols. Antioxidant food supplements in human health: Elsevier; 1999:393-410. https:// doi.org/10.1016/B978-012543590-1/50027-5

2. Apel K, Hirt H. Reactive oxygen species: metabolism, oxidative stress and signal transduction. Annu Rev Plant Biol. 2004;55: 373-99. https://doi.org/10.1146/annurev.arplant.55.031903.141701

3. Gill SS, Tuteja N. Reactive oxygen species and antioxidant machinery in abiotic stress tolerance in crop plants. Plant Physiology and Biochemistry. 2010;48(12):909-30. https://doi.org/ 10.1016/j.plaphy.2010.08.016

4. Pascual J, Rahikainen M, Kangasjärvi S. Plant light stress. eLS. 2017:1-6. https://doi.org/10.1002/9780470015902.a0001319.pub3

5. Romani A, Pinelli P, Galardi C, Sani G, Cimato A, Heimler D. Polyphenols in greenhouse and open-air-grown lettuce. Food Chemistry. 2002;79(3):337-42. https://doi.org/10.1016/S03088146(02)00170-X

6. Darko E, Heydarizadeh P, Schoefs B, Sabzalian MR. Photosynthesis under artificial light: the shift in primary and secondary metabolism. Philosophical Transactions of the Royal Society B: Biological Sciences. 2014;369(1640):20130243. https://doi.org/ 10.1098/rstb.2013.0243

7. Matysiak B, Kowalski A. White, blue and red LED lighting on growth, morphology and accumulation of flavonoid compounds in leafy greens. Zemdirbyste-Agriculture. 2019;106(3). https:// doi.org/10.13080/z-a.2019.106.036

8. Dou H, Niu G, Gu M, Masabni JG. Effects of light quality on growth and phytonutrient accumulation of herbs under controlled environments. Horticulturae. 2017;3(2):36. https:// doi.org/10.3390/horticulturae3020036

9. Manukyan A. Effects of PAR and UV-B radiation on herbal yield, bioactive compounds and their antioxidant capacity of some 
medicinal plants under controlled environmental conditions. Photochemistry and Photobiology. 2013;89(2):406-14. https:/ doi.org/10.1111/j.1751-1097.2012.01242.x

10. Christie JM. Phototropin blue-light receptors. Annu Rev Plant Biol. 2007;58:21-45 2 https://doi.org/10.1146/ annurev.arplant.58.032806.103951

11. Bantis F, Smirnakou S, Ouzounis T, Koukounaras A, Ntagkas N Radoglou K. Current status and recent achievements in the field of horticulture with the use of light-emitting diodes (LEDs). Scientia Horticulturae. 2018;235:437-51. https://doi.org/10.1016/j. scienta.2018.02.058

12. Muneer S, Kim EJ, Park JS, Lee JH. Influence of green, red and blue light emitting diodes on multiprotein complex proteins and photosynthetic activity under different light intensities in lettuce leaves (Lactuca sativa L.). International Journal of Molecular Sciences. 2014;15(3):4657-70. https://doi.org/10.3390/ ijms15034657

13. Wang $\mathrm{X}, \mathrm{Xu} \mathrm{X}$, Cui J. The importance of blue light for leaf area expansion, development of photosynthetic apparatus and chloroplast ultrastructure of Cucumis sativus grown under weak light. Photosynthetica. 2015;53(2):213-22. https://doi.org/ 10.1007/s11099-015-0083-8

14. Ouzounis T, Razi Parjikolaei B, Fretté X, Rosenqvist E, Ottosen CO. Predawn and high intensity application of supplemental blue light decreases the quantum yield of PSII and enhances the amount of phenolic acids, flavonoids and pigments in Lactuca sativa. Frontiers in Plant Science. 2015;6:19. https://doi.org/ 10.3389/fpls.2015.00019

15. Baker NR. Chlorophyll fluorescence: a probe of photosynthesis in vivo. Annu Rev Plant Biol. 2008;59:89-113. https://doi.org/ 10.1146/annurev.arplant.59.032607.092759

16. Kalaji HM, Schansker G, Brestic M, Bussotti F, Calatayud A, Ferroni L, Goltsev V, Guidi L, Jajoo A, Li P. Frequently asked ques tions about chlorophyll fluorescence, the sequel. Photosynthesis Research. 2017;132(1):13-66. https://doi.org/10.1007/s11120-0160318-y

17. Klughammer C, Schreiber U. Complementary PS II quantum yields calculated from simple fluorescence parameters measured by PAM fluorometry and the saturation pulse method. PAM Application Notes. 2008;1(2):201-47. https://walz.com/ downloads/pan/PAN078007.pdf

18. Ouzounis T, Rosenqvist E, Ottosen C-O. Spectral effects of artificial light on plant physiology and secondary metabolism: a re view. HortScience. 2015;50(8):1128-35. https://doi.org 10.21273/HORTSCI 50.8.1128

19. Sasikumar JM, Maheshu V, Aseervatham G, Darsini D. In vitro antioxidant activity of Hedyotis corymbosa (L.) Lam. aerial parts. 2010. http://nopr.niscair.res.in/handle/123456789/7464

20. Le TA, Hoang TTT, Phan HN. Development of shoots of Hedyotis corymbosa (L.) Lam. in vitro culture. Science and Technology Development Journal. 2015;18(4):75-84. https://doi.org/ 10.32508/stdj.v18i4.911

21. TM, FSA revised medium for rapid growth and bio assays with tobacco tissue cultures. Physiologia Plantarum. 1962;15(3):47397. https://doi.org/10.1111/j.1399-3054.1962.tb08052.x

22. Wellburn AR. The spectral determination of chlorophylls a and b as well as total carotenoids, using various solvents with spec trophotometers of different resolution. Journal of Plant Physiology. 1994;144(3):307-13. https://doi.org/10.1016/S01761617(11)81192-2

23. Coombs J, Hind G, Leegood R, Tieszen L, Vonshak A. Analytical techniques. Techniques In Bioproductivity and Photosynthesis: Elsevier; 1985:219-28. https://doi.org/10.1016/B978-0-08-0319995.50027-3

24. Baba SA, Malik SA. Determination of total phenolic and flavonoid content, antimicrobial and antioxidant activity of a root extract of Arisaema jacquemontii Blume. Journal of Taibah University for Science. 2015;9(4):449-54. https://doi.org/10.1016 j.jtusci.2014.11.001

25. Powles SB. Photoinhibition of photosynthesis induced by visible light. Annual Review of Plant Physiology. 1984;35(1):15-44. https://doi.org/10.1146/annurev.pp.35.060184.000311

26. Tanaka R, Tanaka A. Chlorophyll b is not just an accessory pigment but a regulator of the photosynthetic antenna. Porphyrins. 2000;9(1):240-45

27. Oster U, Tanaka R, Tanaka A, Rüdiger W. Cloning and functional expression of the gene encoding the key enzyme for chlorophyll $\mathrm{b}$ biosynthesis (CAO) from Arabidopsis thaliana. The Plant Journal. 2000;21(3):305-10. https://doi.org/10.1046/j.1365313x.2000.00672.x

28. Son KH, Park JH, Kim D, Oh MM. Leaf shape index, growth and phytochemicals in two leaf lettuce cultivars grown under monochromatic light-emitting diodes. Horticultural Science and Technology. 2012;30(6):664-72. https://doi.org/10.7235/ hort.2012.12063

29. Bantis F, Ouzounis T, Radoglou K. Artificial LED lighting enhances growth characteristics and total phenolic content of Ocimum basilicum, but variably affects transplant success. Scientia Horticulturae. 2016;198:277-83. https://doi.org/10.1016/ j.scienta.2015.11.014

30. Heo JW, Kang DH, Bang HS, Hong SG, Chun CH, Kang KK. Early growth, pigmentation, protein content and phenylalanine ammonia-lyase activity of red curled lettuces grown under different lighting conditions. Horticultural Science and Technology. 2012;30(1):6-12. https://doi.org/10.7235/hort.2012.11118

31. Johkan M, Shoji K, Goto F, Hashida S-n, Yoshihara T. Blue lightemitting diode light irradiation of seedlings improves seedling quality and growth after transplanting in red leaf lettuce. HortScience. 2010;45(12):1809-14. https://doi.org/10.21273/ HORTSCI.45.12.1809

32. Park CH, Kim NS, Park JS, Lee SY, Lee JW, Park SU. Effects of light-emitting diodes on the accumulation of glucosinolates and phenolic compounds in sprouting canola (Brassica napus L.). Foods. 2019;8(2):76. https://doi.org/10.3390/foods8020076

33. Gam DT, Khoi PH, Ngoc PB, Linh LK, Hung NK, Anh PTL, Thu NT, Hien NTT, Khanh TD, Ha CH. LED lights promote growth and flavonoid accumulation of Anoectochilus roxburghii and are linked to the enhanced expression of several related genes. Plants. 2020;9(10):1344. https://doi.org/10.3390/plants9101344

34. Jung WS, Chung IM, Hwang MH, Kim SH, Yu CY, Ghimire BK. Application of light-emitting diodes for improving the nutritional quality and bioactive compound levels of some crops and medicinal plants. Molecules. 2021;26(5):1477. https://doi.org/ 10.3390/molecules26051477

\section{Additional information}

Peer review information: Plant Science Today thanks Sectional Editor and the other anonymous reviewers for their contribution to the peer review of this work.

Reprints and permissions information is available at https://horizonepublishing.com/journals/index.php/PST/open_access_policy

Publisher's Note: Horizon e-Publishing Group remains neutral with regard to juris dictional claims in published maps and institutional affiliations.

To cite this article: Le A T, Phan N H, Do T K. Effect of blue light on the photosynthesis and flavonoid accumulation in leaves of Hedyotis corymbosa (L.) Lam. Plant Science Today. 2021;8(4):955-962. https://doi.org/10.14719/pst.2021.8.4.1238

Plant Science Today, published by Horizon e-Publishing Group, is covered by Scopus, Web of Science, BIOSIS Previews, Clarivate Analytics, etc. See https://horizonepublishing.com/journals/index.php/PST/indexing abstracting 